\title{
AN ANALYSIS OF PRESCRIBING OF AN HYPNOTIC IN THE COMMUNITY
}

\author{
O. L. WADE AND H. E. HOOD \\ University of Birmingham and The Queen's University of Belfast
}

In Northern Ireland all prescriptions written by family doctors are sent to the Northern Ireland General Health Services Board so that pharmacists may be paid. The opportunity has been taken to analyse the prescribing of drugs or groups of drugs and changes in prescribing between 1966 and 1970.

In this paper the prescribing of an hypnotic preparation, Mandrax, ${ }^{*}$ is described. Differences of prescribing in different practices and geographical differences are reported and a study of the high prescribers of the preparation has been carried out. The paper is the first of a number which examine critically the prescribing of drugs by family doctors in the community.

The work described in this paper began after the thalidomide disaster in 1961. Everyone who investigated the cause of the increase in the birthrate of phocomelic infants at that time found great difficulty in ascertaining whether the mothers had been prescribed thalidomide during their pregnancy. Doctors had seldom kept any records of the drugs prescribed and the memory of both patients and doctors of what had taken place several months previously was so imperfect as to be valueless. It was Speirs (1962), working in Stirlingshire, who conceived the idea of examining National Health Service prescription scripts. He was able to obtain documentary proof that thalidomide had been prescribed during the pregnancy of 8 out of 10 women who had given birth to deformed children but who had denied, as did their family doctors, that the drug had ever been prescribed for them. To achieve these results, however, Speirs had to make a long and tedious search through thousands of prescription scripts written in central Scotland during the relevant period of time.

Wade (1966) found that a similar search could be made much more rapidly in Northern Ireland where details of all prescriptions were more readily accessible. This was because in 1952 the Northern Ireland General Health Services Board pricing bureau had introduced a system of mechanized data

* Mandrax is the trade name for Roussel's preparation of methaqualone and diphenhydramine. processing to increase the speed and accuracy of payments made to pharmacists for their National Health Service dispensing. Under the system every pharmacist returned to the Board each month all scripts dispensed by him, and the pricing bureau transcribed the data on to Hollerith cards. It was a quick and easy process to re-sort the cards mechanically and identify the script numbers of all prescriptions written for a particular drug. By this means, information about the prescribing of any drug by any or every doctor in the Province could be examined monthly and, if necessary, the original scripts, bearing the name and address of the patient for whom the drug had been prescribed, could be traced from the script serial number. It took several days to trace all the scripts but this was much quicker than the slow and tedious search which had had to be undertaken at Stirling.

The first investigation using the facilities of the Northern Ireland General Health Services Board pricing bureau was on the prescribing of chloramphenicol (Wade, 1966), and other smaller investigations were carried out for the Committee on Safety of Drugs. In 1966 the Hollerith card system with its relatively slow mechanical sorting was replaced by a more modern data processing system using the Northern Ireland Government computer. All analyses became easier and less onerous and were much less demanding of machine operator time which had seriously limited the scope of the earlier studies based on the Hollerith system. It became possible to plan studies of the prescribing of a number of drugs month by month over a prolonged period of time and to examine their use by doctors in different areas of Northern Ireland.

This paper describes the methods used and the results obtained in an analysis of the prescribing of an hypnotic preparation between July 1966 and the present day. The preparation chosen for study was Mandrax, a compound containing methaqualone $250 \mathrm{mg}$ and diphenhydramine $25 \mathrm{mg}$. It was first marketed in September 1965 shortly before the computer facilities became available in April 1966. Although this preparation had no obvious advantage 
over other non-barbiturate hypnotics it was being strongly promoted and it seemed likely that its prescribing would increase greatly.

\section{Data Processing}

\section{MeTHODS}

Every commonly used drug and pharmaceutical preparation, supplied by pharmacists in contract with the Northern Ireland General Health Services Board, is allotted code numbers. The code numbers for Mandrax are 2588, 2601, and 3198. These indicate the pack size from which the pharmacist has supplied the tablets or capsules. When a patient hands in a prescription the pharmacist endorses it with his pharmacy code number and with codes which identify the preparation supplied, its dose form, and the quantity supplied, and returns it to the Board at the end of the month. This information, together with the code numbers of the script and of the doctor who wrote it, is transferred to computer tape for pricing purposes but it was possible, with a special programme, to obtain each month information about every prescription written for any preparation. The total number of prescriptions written for Mandrax, the total quantities supplied, the dose forms, and the average amount per prescription were tabulated for each month. The code numbers of the doctors who wrote the prescriptions and the pharmacists who dispensed them were recorded so that it was possible to analyse the prescribing of individual doctors or of individual practices.

\section{ANALYSES OF Prescribing}

The following analyses were made of the prescribing of Mandrax:

(1) The total number of prescriptions written and the total quantity prescribed in the whole Province were examined for every month between July 1966 and April 1971, and a comparison was made of the number of prescriptions for Mandrax and for nine other widely used hypnotics in the month of October each year from 1966 to 1970.

(2) An analysis was made of the quantities of Mandrax prescribed in every practice in Northern Ireland during the three-month period July to September 1966 and for the same three months in 1969. Although it would have been desirable to look at the prescribing of each individual doctor, it was found that in partnerships the job of ordering prescription pads often fell to one member of the partnership and prescription scripts, overprinted with his code number, were used by the other doctors in the firm.

In 1966 there were 476 practices in Northern Ireland. Thirty-two of these had fewer than 500 patients and were omitted from the survey as it was $:$ thought that the patterns of prescribing might be unduly distorted in practices of such small size. The $?$ number of practices included in the survey was $\overrightarrow{\vec{F}}$ therefore 444 . In 1969 the prescribing of 443 practices was similarly analysed.

A three-month period was chosen for the surveys $\frac{\bar{\sigma}}{\bar{D}}$ to minimize variations in prescribing that might $\overrightarrow{\mathbb{D}}$ occur in a single month due, for example, to doctors' $Q$ holidays or to their different habits of prescribing: some prefer to prescribe small amounts of a drug $\overrightarrow{0}$ frequently while others tend to prescribe several $\vec{\longrightarrow}$ weeks' supply at once.

(3) Analyses were made of the geographical distribution of prescribing of Mandrax in the Province $\stackrel{?}{?}$ during July, August, and September in 1966 and 1969. In order to study the geographical variations in i prescribing, the Province was divided into 65 areas $\vec{N}$ comprising the city of Belfast, the city of London- $\vec{P}$ derry, the large towns, and the smaller towns and 9 villages with their rural fringes, encompassing, $\vec{Z}$ wherever possible, populations of not less than 5,000 registered patients. Figure 1 shows a map of the $65^{2}$

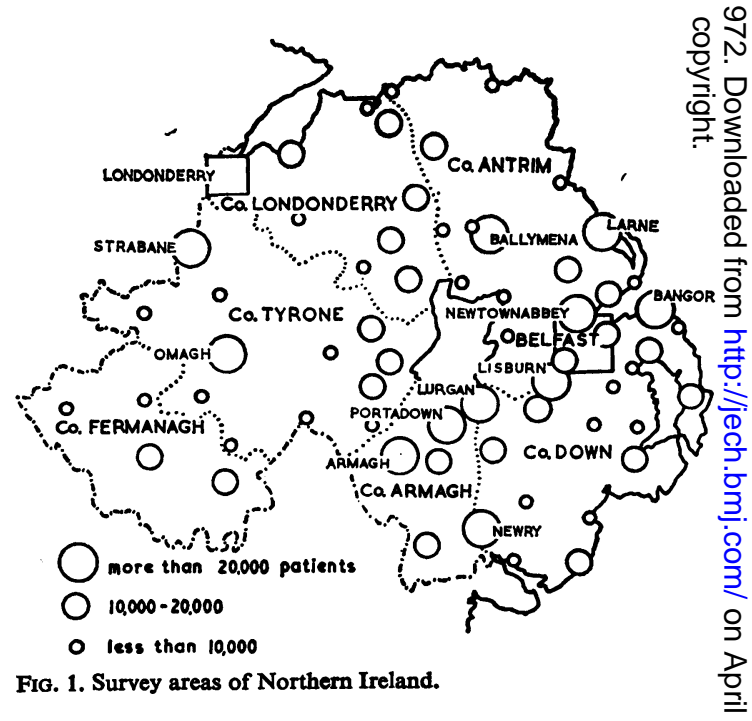

areas. Belfast and Londonderry are indicated on the map by squares. They had populations of $516,324 \mathrm{~N}$ and 75,707 registered patients respectively in 1966.N The other towns and villages are represented by ${ }_{\sigma}^{\omega}$ circles the size of which is proportional to the size of the registered population of the area. It was convenient sometimes to compare prescribing in Belfastos and the six counties, and the county boundaries are shown in Figure 1.

(4) An analysis was made of prescribing by in $-\frac{D}{D}$ dividual doctors who were arbitrarily designated 
high prescribers of Mandrax (those writing 30 or more prescriptions per month) and their prescribing of the preparation was examined month by month over the three-year period July 1966 to June 1969.

\section{RESULTS}

Changes in Number of Prescriptions written 1966-71

The monthly prescribing of Mandrax shows a pattern of steadily increasing use during 1966 and 1967 followed by a period of fairly constant use in 1968 and 1969 and a decline in use during 1970 and early 1971 (Fig. 2). The pattern of seasonal use of

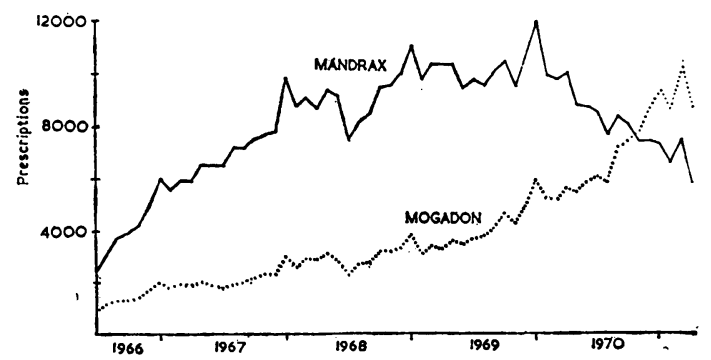

FIG. 2. Number of prescriptions for Mandrax and Mogadon written each month in Northern Ireland, July 1966-April 1971.

Mandrax shows high prescribing in January each year, in common with prescribing in general, possibly as a result of winter gloom setting in after the Christmas festivities, and low prescribing in July and August, the holiday months.
Prescribing of Mandrax increased from 2,400 prescriptions for 91,000 tablets in July 1966 , when data first became available, to a maximum of 12,000 prescriptions for 570,000 tablets in January 1970 but fell to 5,662 prescriptions for 292,000 tablets in April 1971, approximately the level of prescribing pertaining early in 1967.

Between the years 1966 and 1970 the use of hypnotic drugs, in the month of October, increased by $25 \%$ from 33,000 to 41,000 prescriptions. Mandrax made up an increasingly large share of hypnotic prescribing, accounting for $12 \%$ of the total in 1966 and $25 \%$ of the total in 1969 but its share decreased to $20 \%$ of the total in 1970 , apparently due to the increased prescribing of nitrazepam (Mogadon*) (Fig. 3). The prescribing of Mogadon rose gradually from 1,000 prescriptions per month in July 1966 to 3,000 prescriptions per month by January 1968 and, apart from slight seasonal variations, remained at this figure for the next 18 months. Since mid-1969, prescribing of Mogadon increased sharply to over 10,000 prescriptions in the month of March 1971, and exceeded prescribing of Mandrax for the first time in September 1970.(Fig. 2).

\section{Differences in Prescribing in Practices}

In 1966, over the three-month period of the survey, there were 76 practices $(17 \%$ of all practicès analysed) in Northern Ireland in which no Mandrax was prescribed and $26(6 \%)$ where Mandrax was prescribed at a rate greater than 800 tablets per

- Mogadon is the trade name for nitrazepam
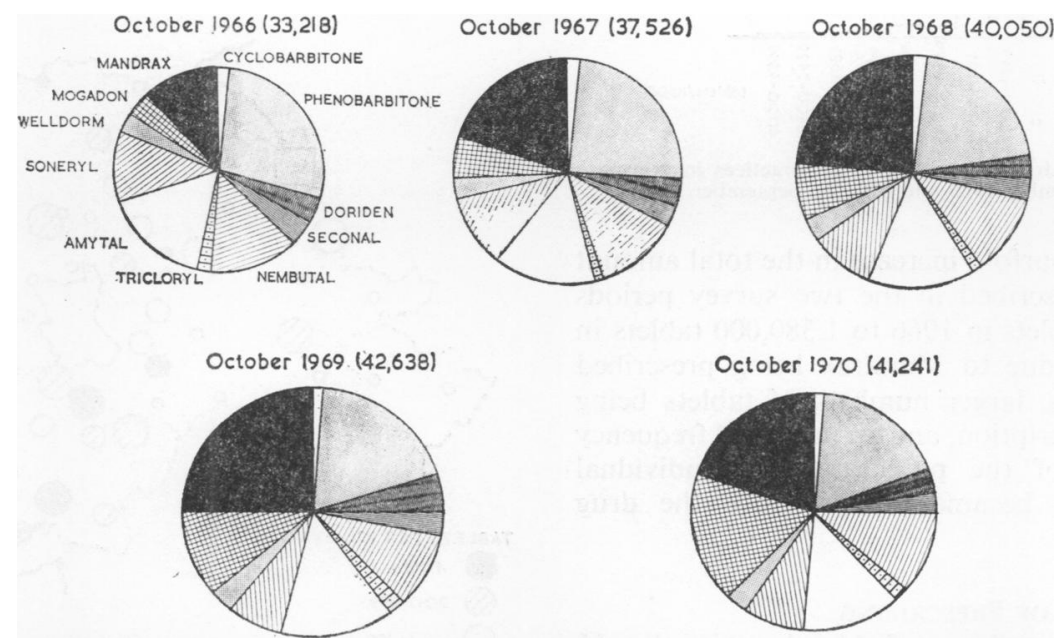

FIG. 3. Changes in prescribing of Mandrax and 10 other hypnotic preparations in the month of October each year 1966-70. Total hypnotic prescriptions for each month in parentheses.

Mandrax prescriptions were $12 \%$ of the total in $1966,20 \%$ in $1967,24 \%$ in $1968,25 \%$ in 1969 , and $20 \%$ in 1970 . 
thousand list patients. In 1969 only 12 practices (3\%) prescribed no Mandrax and $202(45 \%)$ practices prescribed more than 800 tablets per thousand patients. The maximum amount of Mandrax prescribed by any practice in 1966 was 2,000 tablets per thousand list patients; the maximum had doubled by 1969 (Fig. 4).

(a)

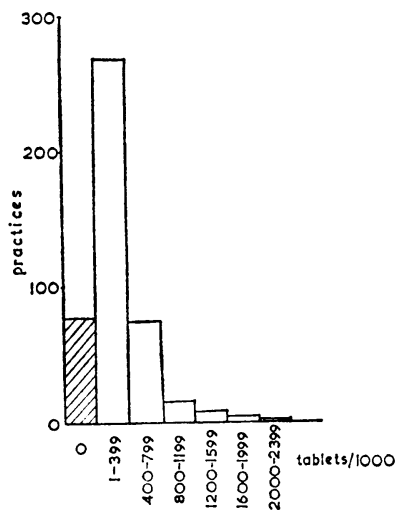

(b)

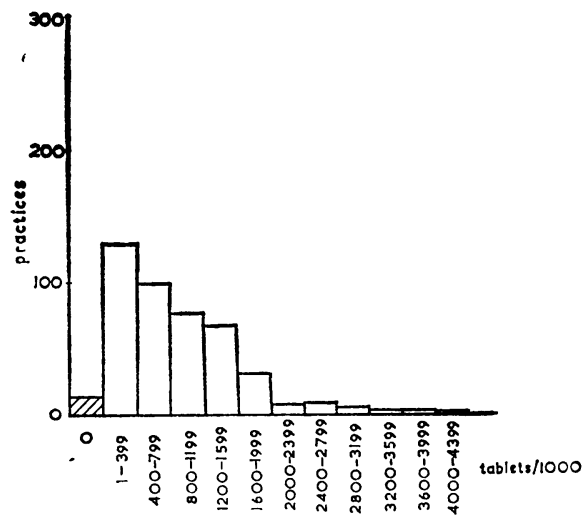

FIG. 4. Rate of Mandrax prescribing in all practices in Northern Ireland (a) July-September 1966 and (b) July-September 1969.

There was a fourfold increase in the total amount of Mandrax prescribed in the two survey periods from 345,000 tablets in 1966 to $1,380,000$ tablets in 1969. This was due to Mandrax being prescribed by more doctors, larger numbers of tablets being ordered per prescription, and an increased frequency of prescribing of the preparation by individual doctors as they became familiar with the drug (Fig. 5).

\section{The Geography of Prescribing}

When the prescribing of Mandrax in the 65 different areas of the Province was examined, it was found that the great increase in prescribing that

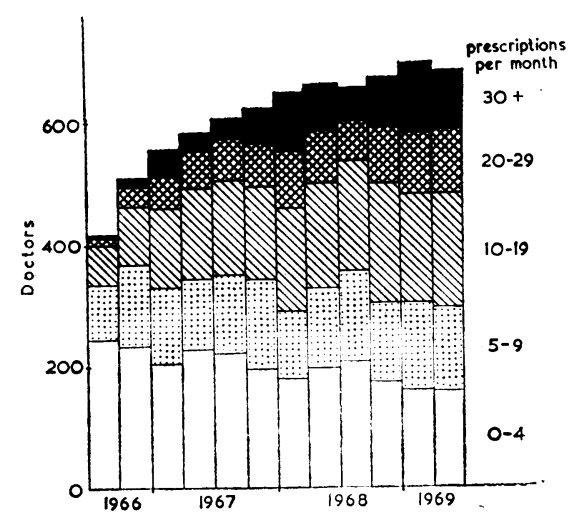

FIG. 5. Number of prescriptions for Mandrax written by general practitioners in Northern Ireland in the months July, October, January and April during the three-year period July 1966-June 1969.

occurred between 1966 and 1969 had been unevenly distributed. In 1966 an average of 242 tablets per thousand list patients was prescribed throughout the Province. Table I shows that the prescribing was heaviest in County Armagh and County Fermanagh. This was surprising for in most surveys so far carried out Co. Fermanagh has always been distinguished by the low prescribing of all drugs by general practitioners. By 1969 there had been a three or fourfold increase of prescribing of Mandrax in alko areas except in Co. Fermanagh where the quantity prescribed had only doubled, so that the County was by 1969 the area with the lowest rate of prescribing of Mandrax.

A detailed analysis of the prescribing of Mandrax in the 65 different areas is given for 1966 in Fig. 6,

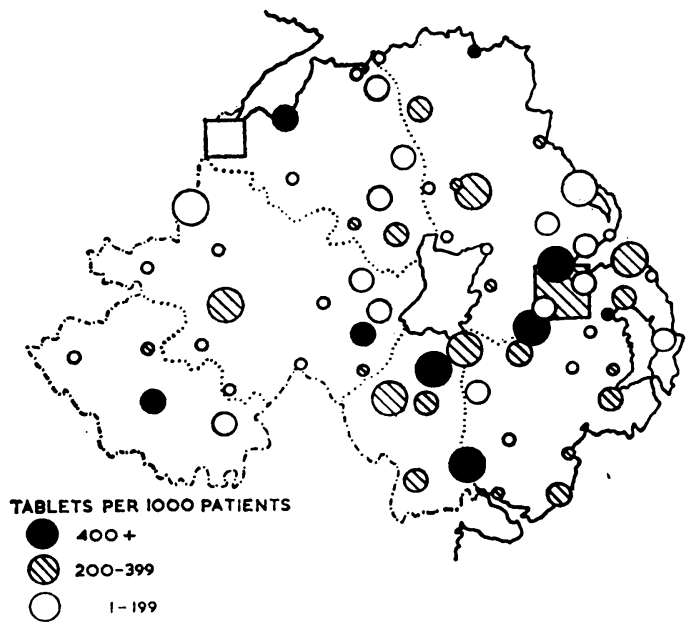
FIG. 6. Geographical distribution of the rate of Mandrax prescribing
in Northern Ireland during the three-month period July-September 1966. 


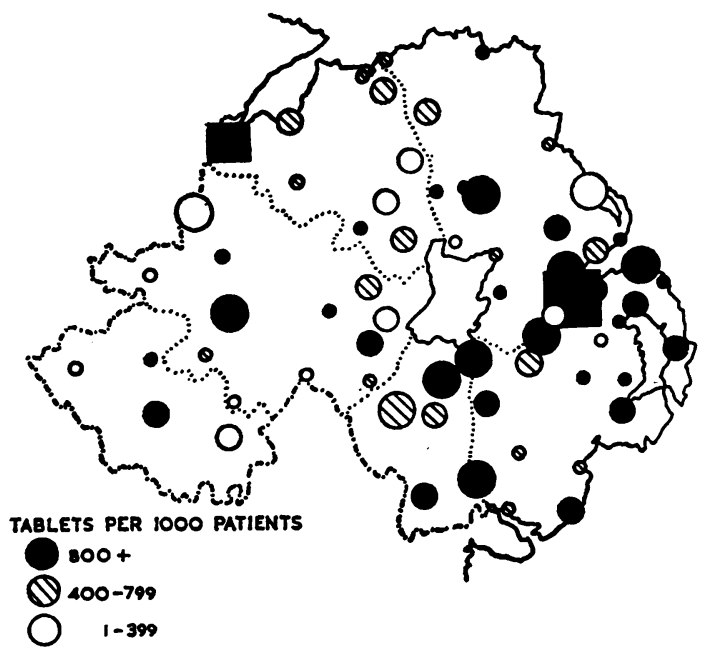

Fig. 7. Geographical distribution of the rate of Mandrax prescribing in Northern Ireland during the three-month period July-September 1969.

and for 1969 in Figure 7. This shows a trend for higher prescribing in the east of the Province compared with the west. There were two small towns in Co. Down where the prescribing of Mandrax changed dramatically. In one town with three singlehanded practices, the doctors prescribed on average 160 tablets per thousand patients over the threemonth period in 1966, and in the same three-month period of 1969 they prescribed 3,228 tablets per thousand patients, enough for every person in the town to have one tablet every month. In 1966 there were two small towns in which no Mandrax was prescribed and another in which only 5 tablets per thousand persons were prescribed. By 1969 there were no areas in which Mandrax was not prescribed but there were two towns in Co. Tyrone where only
77 or 78 tablets per thousand patients were prescribed during the survey. These figures indicate the tremendous variations in prescribing of a single drug that may be found.

\section{The Pattern of 'High' Prescribing by INDIVIDUAL DOCTORS}

The number of doctors prescribing Mandrax rose from 412 (54\% of all doctors in the Province) between April and June 1966 to 674 (89\%) in the same months of 1969 . Not only did more doctors prescribe Mandrax each month but, as each doctor added it to his repertoire, the number of prescriptions and the quantities he prescribed per month increased (Fig. 8).

In July 1966 there were only two doctors in the Province who wrote more than 30 prescriptions per month for Mandrax but in the peak month for 'high' prescribing doctors, January 1969, 110 doctors wrote more than 30 prescriptions per month including three who each wrote more than 100 prescriptions for Mandrax in that month.

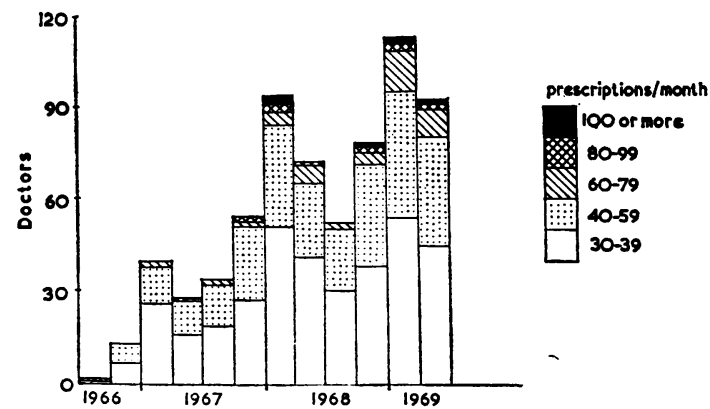

FIG. 8. Number of doctors who were 'high' prescribers of Mandrax in the months July, October, January, and April throughout the threeyear period, July 1966 -June 1969 , showing the number of prescriptions written by them in each of these months.

TABLE I

DISTRIBUTION OF PRESCRIBING OF MANDRAX APRIL-JUNE 1966 AND 1969

\begin{tabular}{|c|c|c|c|c|c|c|}
\hline \multirow[t]{2}{*}{ Area } & \multicolumn{2}{|c|}{$\begin{array}{l}\text { Registered Patients } \\
\text { ( } \% \text { of total) }\end{array}$} & \multicolumn{2}{|c|}{$\begin{array}{l}\text { Mandrax Tablets Prescribed } \\
\text { ( } \% \text { of total) }\end{array}$} & \multicolumn{2}{|c|}{$\begin{array}{c}\text { Tablets Prescribed per 1,000 } \\
\text { Registered Patients }\end{array}$} \\
\hline & 1966 & 1969 & 1966 & 1969 & 1966 & 1969 \\
\hline Belfast & 513,958 & 520,527 & 116,497 & 494,726 & 227 & 950 \\
\hline Co. Antrim & & 279,980 & 67,725 & 234,029 & 284 & 836 \\
\hline Co. Armagh & & 116,183 & 35,752 & 122,558 & 332 & 1,055 \\
\hline & 223,870 & 248,763 & 59,895 & 282,888 & 268 & 1,137 \\
\hline Co. Fermanagh & 38,397 & 53,786 & 11,532 & 32,305 & 300 & 601 \\
\hline Co. Tyrone & $\begin{array}{l}168,566 \\
(12 \%)\end{array}$ & 177,032 & 30,716 & 117,466 & 182 & 664 \\
\hline Co. Londonderry & 135,847 & 146,955 & 22,987 & 96,073 & 170 & 654 \\
\hline Whole Province & $\begin{array}{r}1,427,150 \\
(100 \%)\end{array}$ & $\begin{array}{r}1,543,226 \\
(100 \%)\end{array}$ & $\begin{array}{l}345,104 \\
(100 \%)\end{array}$ & $\begin{array}{r}1,380,045 \\
(100 \%)\end{array}$ & 242 & 894 \\
\hline
\end{tabular}


TABLE II

PERSISTENCE OF 'HIGH' PRESCRIBING OF MANDRAX (OVER 30 PRESCRIPTIONS PER MONTH) AT THREE-MONTHLY INTERVALS, OF DOCTORS WHO BECAME NEW 'HIGH' PRESCRIBERS IN JULY, OCTOBER, JANUARY, AND APRIL THROUGHOUT THE THREE-YEAR PERIOD JULY 1966-JUNE 1969

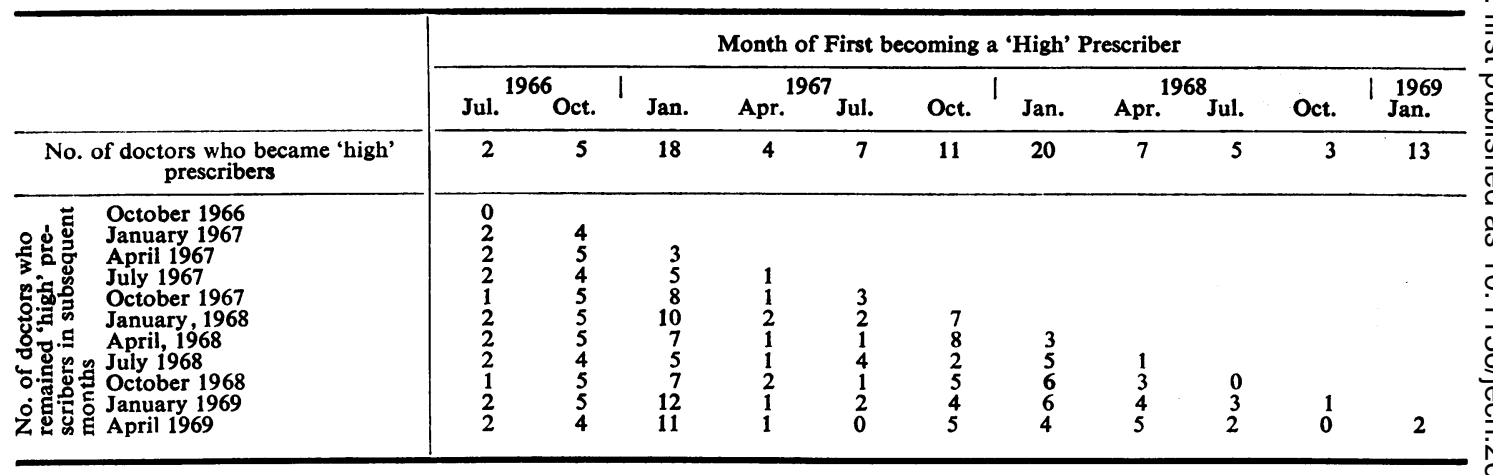

It is arbitrary to define a doctor as a 'high' prescriber of a drug solely by the number of prescriptions he writes per month. It would be more accurate to consider the quantities he prescribed in relation to the number of patients on his list. A pilot study showed, however, that the number of prescriptions written per month by the doctor correlates closely with the more elaborate analysis although both methods may be a little unreliable because doctors may use prescription pads endorsed with the number of other doctors in the partnership.

Examination of those doctors who wrote more than 30 prescriptions for Mandrax in any month ('high' prescribers) showed that once a doctor became a 'high' prescriber he tended to remain a 'high' prescriber; for example, the two 'high' prescribing doctors in the first month of the survey, July 1966, remained high prescribers except for the months of October 1966, 1967, and 1968 to the end of the survey in June 1969 (Table II).

Each January there was a wave of doctors who achieved for the first time the sobriquet of 'high' prescriber, but often the high prescribing of these doctors did not persist (Table II).

During the first year of the survey, there were 78 'high' prescribers of Mandrax-doctors who had written more than 30 prescriptions in any one month. In the second year, $68(87 \%)$ of these doctors remained 'high' prescribers for at least one month; in the third year, $62(80 \%)$ of the first year's high prescribers were still high prescribers in at least one month. Doctors who became 'very high' prescribers (more than 60 prescriptions per month) maintained their status in this category with even greater consistency.

Almost one-third of all doctors in the Province were 'high' prescribers for at least one month of the survey and $39(5 \%)$ doctors had been 'very high' prescribers for at least one month before the survey $\stackrel{\vec{N}}{\vec{N}}$ ended. Belfast contained a larger proportion of $\vec{\sim}$ 'high' prescribers ( $40 \%)$ than would be expected for 윽 its proportion of the Province's doctors (31\%). The three western counties had smaller proportions of the 'high' prescribers $(13 \%)$ while containing $25 \%$ of the Province's doctors (Table III).

It would appear that the 'high' prescriber of $N$ Mandrax is most often a single-handed practitioner If he was in a group practice it was most usual fơ him to be the only 'high' prescriber in the practice; only one-third of 'high' prescribing doctors in partnership had partners who were also high prescribers.

\section{ConClusions}

These analyses of the prescribing of Mandrax throw light on features of prescribing which must be familiar to many who work in the pharmaceutical industry. The great increase in the use of Mandrax between 1966 and 1969 and the subsequent decrease is typical of the 'life cycle' of many newly introduced pharmaceutical preparations. Perhaps the initial

TABLE III

DISTRIBUTION OF DOCTORS WHO WERE 'HIGH' PRE- $O$ SCRIBERS OF MANDRAX AT ANY TIME DURING THE THREE-YEAR PERIOD JULY 1966-JUNE 1969

\begin{tabular}{|c|c|c|c|}
\hline \multirow{2}{*}{ Area } & \multicolumn{3}{|c|}{ Doctors } \\
\hline & $\begin{array}{c}\text { Total } \\
\text { Number }\end{array}$ & $\begin{array}{c}\text { 'High' } \\
\text { Prescribers }\end{array}$ & $\begin{array}{l}\text { 'Very High' } \\
\text { Prescribers }\end{array}$ \\
\hline $\begin{array}{l}\text { Belfast } \\
\text { Co. Antrim } \\
\text { Co. Armagh } \\
\text { Co. Down } \\
\text { Co. Fermanagh } \\
\text { Co. Londonderry } \\
\text { Co. Tyrone }\end{array}$ & $\begin{array}{c}293(31 \%) \\
147(19 \%) \\
59(8 \% \%) \\
127(17 \%) \\
35(5 \%) \\
82(11 \%) \\
69(9 \%)\end{array}$ & $\begin{array}{l}96(40 \%) \\
40(16 \%) \\
26(11 \%) \\
50(20 \%) \\
5(2 \%) \\
14(6 \%) \\
13(5 \%)\end{array}$ & $\begin{array}{l}17(44 \%) \\
2(5 \%) \\
4(10 \%) \\
11(28 \%) \\
3(8 \%) \\
2(5 \%)\end{array}$ \\
\hline Whole Province & $758(100 \%)$ & $244(100 \%)$ & $39(100 \%)$ \\
\hline
\end{tabular}


rise in prescribing is due to the dissatisfaction of doctors and of patients with the drugs already on the market. Possibly a similar motive, the wish to use something new, accounts for the subsequent fall in the volume of prescribing when some newer preparation becomes available. These cycles of popularity of different drugs may be an expression of an expectation of the effectiveness of drugs which can never be achieved.

The factors which influence the rise and then the fall in prescribing of a preparation deserve further study. Most doctors must have been recruited to the ranks of those who prescribed Mandrax as a result of visits from the firm's representatives, of reading advertisements or of recommendations from colleagues. It is important to determine in future surveys the nature of the information which the individual doctor regards as adequate to justify the use of a new preparation. There is a possibility that some doctors are prone to be the early users of new preparations. Once the use of a preparation has been adopted there is evidence from previous studies (Wade, 1966) that it is likely to persist for quite a time.

Although wide differences in the prescribing of Mandrax in different practices were expected and were found, the differences in the overall prescribing in different areas of Northern Ireland were unexpected. Mandrax, like most other drugs that have been so far studied, was less prescribed in the western areas of Northern Ireland than in the east of the Province. The explanation for this is not clear. It is not enough to suggest that it is related to differences of urban and rural life, for analyses of prescribing costs in the United Kingdom have shown that areas of Wales and Scotland as well as Northern Ireland have higher prescribing costs than industrial areas of England. High prescribing costs were found to correlate with high rates of sickness benefit and high rates of unemployment and may indicate differences in the incidence, pattern or duration of illnesses (Report of a Health Advisory Committee, 1969). Rosch (1969) found in rural areas of France that prescribed medicines were less used than in urban areas, but that the purchase of over-thecounter medicines accounted for a larger proportion of family expenditure.

Examination of prescribing data from Norway made available to us by courtesy of Norsk Medinisk Depot shows low prescribing areas in the north of Norway and high prescribing areas in the south-east around Oslo. These differences may be similar to those between the western and the eastern areas of Northern Ireland.

The main defect of the studies described in this paper is the difficulty in relating the prescribing of drugs to the needs of individual patients. In the special instance of the prescribing of vitamin $B_{12}$, Cochrane and Moore (1971) were able to show that the prescribing was in excess of the needs of a community. This they were able to do because the prevalence of pernicious anaemia in the community is known. But for the majority of drugs it will be possible to analyse prescribing in relation to the incidence of disease or disability in the population or in relation to the age and sex of the population only when record linkage is developed.

It has been a source of anxiety throughout these investigations that the use of hypnotic drugs in the community is so great. This anxiety is shared by health authorities throughout western Europe, the U.S.A., and eastern Europe where, in recent years, a considerable increase in the use of hypnotics and tranquillizers has been observed. Although there was civil strife in Northern Ireland in the summer of 1969 and during 1970, it was at that time very localized and is unlikely to have influenced prescribing of hypnotics and tranquillizers.

\section{SUMMARY}

An analysis has been made of the prescribing of an hypnotic preparation Mandrax in general practice in Northern Ireland between 1966 and 1970. There was an overall increase in the prescribing of Mandrax and by 1969 one-quarter of all prescriptions for hypnotics were for this preparation. There were great variations from practice to practice, ranging from no prescribing of Mandrax at all in some practices to the prescribing of more than 4,000 tablets per thousand patients per month in others. There were marked geographical variations in the prescribing of Mandrax, less being prescribed in rural and western areas than in Belfast and its environs. Doctors who became frequent prescribers of the drug tended to continue to be frequent prescribers throughout the survey.

We wish to acknowledge a grant in support of this work from the Nuffield Provincial Hospitals Trust and to thank the Officers of the Northern Ireland General Health Services Board and the Government Computer Services for their generous and unstinted help over many years. We are especially indebted to Mr. G. D. Stewart, Dr. R. P. Maybin, and Mr. A. W. Kernahan: without their help these studies would have been impossible.

\section{REFERENCES}

Cochrane, A. L., and Moore, F. (1971). Expected and observed values for the prescription of vitamin $B_{12}$ in England and Wales. Brit. J. prev. soc. Med., 25, 147.

Report of A Health Advisory Committee (1969). Prescribing and Sickness Benefit Costs in Northern Ireland. H.M.S.O., Cmd 528. 
Rosch, G. (1969). L'économie des services de soins médicaux en France. Extract de consommations. Annales du CREDOC Nos. 1 and 2. Dunod. Paris.
SPEIRS, A. L. (1962). Thalidomide and congenital abnormalities. Lancet, 1, 303.

WADE, O. L. (1966). Prescribing of chloramphenicol and aplastic anaemia. J. Coll. gen. Practit., 12, 277. 